Abstracts on this page have been chosen and edited by Dr Trevor Watts

\section{ENDODONTICS; MEDICINE}

\section{The effect of human immunodeficiency virus on endodontic treatment outcome}

Quesnell BT, Alves M et al. J Endodon 2005; 31: 633-636

Endodontic outcome was similar in HIV infected patients and healthy controls.

The aim of endodontic therapy for necrotic pulps may be stated as reduction of intra- and extraradicular microbes to a level where host defence can resolve infection and allow complete healing. When patients are immunocompromised, this level may be altered, and a quoted study of diabetics showed lower longterm success.

In the present study, preoperative and 1 yr follow-up radiographs were examined in 33 HIV positive and 33 control patients, and the Periapical Index (PAI) was used to evaluate periapical radiolucencies by 3 independent examiners. In the HIV group, mean PAI reduced from 3.74 to 2.42 , and in the control group, from 3.94 to 2.25 (inter-group difference NS). In both groups, $88 \%$ of patients showed improvements. The authors comment that recent HIV treatments such as HAART lead to improved host defences and the outcome is not unexpected.

doi:10.1038/sj.bdj.4813070

FIXED PROSTHODONTICS; PERIODONTICS

Retrospective evaluation of complete-arch fixed partial dentures connecting teeth and implant abutments in patients with normal and reduced periodontal support

Cordaro L, Ercoli C et al. J Prosthet Dent 2005; 94: 313-320

The habit of missing meals, particularly breakfast, was significantly associated with caries.

The role of sugar in caries has been related to the manner in which it is consumed. This study was a 3 year investigation of behaviour in relation to caries, in 162 girls initially aged 12 yrs and receiving regular dental care in a small Swedish town. Caries increased over the period from a mean DMFT of 1.47 to 2.56. Four odds ratios were significant at the 5\% level for caries increment greater than the mean: omitting breakfast (OR $=4.9)$, omitting dinner (2.8), irregular main meals (3.1) and smoking (4.1). Omitting school lunch, snacking, and omitting toothbrushing did not reach significance.

The authors discuss the possible relationships of smoking and meal omission in relation to caries, and advise that regular meals should be recommended, with an emphasis on breakfast.

\section{TRAUMA; CHILD ABUSE}

Injuries to the head, face, mouth and neck in physically abused children in a community setting

Cairns AM, Mok JYQ et al. Int J Paediatr Dent 2005; 15: 310-318

About $60 \%$ of the children examined had orofacial signs which a general dental practitioner would be expected to identify.

So far, no study has identified the prevalence of orofacial injury in physically abused children. This study examined the records of 390 children who were under the age of 16 yrs over a $5 \mathrm{yr}$ period and for whom physical abuse was suspected. The identification of such records was subject to others being removed because the child had reached 16 yrs of age, or because some were in use or subject to criminal investigation.

In the recovered records, $45 \%$ of children were $<4$ yrs old, over 60\% were boys, and 15\% were known to be on the Child Protection Register. In 230 children, 315 signs of abuse on head, face, mouth or neck were recorded. Most of these (65\%) were facial bruising, followed by facial abrasion (23\%), bruised head (18\%) and bruised neck $(12 \%)$ and other injuries. In more than $60 \%$ of the injuries, the alleged cause was undisclosed, but 23\% had been punched or slapped, 16\% had been beaten with an implement and 16\% had sustained more than 2 mechanisms of assault. The authors emphasize the important place the dental practitioner may have in identifying such abuse.

doi:10.1038/sj.bdj.4813072

IMPLANT DENTISTRY; CLEFT LIP AND PALATE

Dental implants in patients with orofacial clefts: a long-term follow-up study Kramer F-J, Baethge C et al. Int J Oral Maxillofac Surg 2005; 34: 715-721 In these patients, grafting and implants gave satisfactory survival rates.

In patients with cleft lips and palates (CLAP), teeth are often missing, and orthodontic treatment may be used to move posterior teeth forward after bone grafting. Where this is not possible, implants may be considered. In this study, 45 CLAP patients were treated with 75 implants and grafting in maxillary incisor and canine positions, and these were followed for a mean 5.5 yrs, and compared with 45 controls who received implants in normal anterior maxilla (C1), and 45 who had implants combined with grafts (C2).

Implant survival in the CLAP group was $82 \%$ at end of followup, compared with 91\% in C1 $(\mathrm{P}<0.08)$ and $76 \%$ in $\mathrm{C} 2(\mathrm{P}<0.1)$. There were certain overall variations: survival was greater for longer implants $(93 \%)$ than shorter $(62 \%)(\mathrm{P}<0.01)$. However, no other significant effects were found. The authors consider the results for CLAP patients to compare well with other grafted patients.

doi:10.1038/sj.bdj.4813073 